\title{
El reforzamiento de los vínculos comunitarios a través de la fiesta en las ciudades castellanas en el marco de cuadrillas y cofradías. Siglos XV-XVII
}

\author{
The strengthening of community links through the feasts \\ in the Castilian towns. The role of quarter communities \\ (cuadrilla) and religious confraternities (cofradia) \\ in the $15^{\text {th }}$ to $17^{\text {th }}$ centuries
}

\author{
Máximo Diago Hernando \\ Instituto de Historia. CCHS. CSIC. Madrid
}

\section{RESUMEN}

En el período preindustrial en las ciudades europeas se celebraron fiestas de muy variadas características. Con frecuencia éstas fueron organizadas por la autoridad urbana como instrumento de legitimación del orden vigente. Pero también se organizaron celebraciones con una más marcada base popular, que tenían por objetivo reforzar los lazos de solidaridad entre el conjunto de los participantes. Fue el caso de muchas de las fiestas celebradas por las cofradías, pero también de algunas que organizó el conjunto de la población pechera distribuida en cuadrillas. En este trabajo se analiza en profundidad un caso muy original de este último tipo de fiestas, la celebrada por las cuadrillas del Común de pecheros en Soria el primer domingo después de San Juan, que pervive en la actualidad.

Palabras clave: Fiesta urbana, Cofradías, Cuadrillas, Edad Moderna, Soria, San Juan.

\section{SUMMARY}

During the pre-industrial period, festivals of very different kinds took place in the European towns. Very often these festivals were organized by the urban authorities, which used them as a means of legitimization of the established social order. However, festivals with a much more popular base were also organized, whose main aim was to reinforce the solidarity links between the participants. That was the case in many festivals organized by the confraternities, but also in some festivals organized by the quarter communities (cuadrillas) in certain towns. In this article the author analyses a very original festival celebrated since the Middle Ages to the present day in the Castilian town of Soria on the first Sunday after the Feast of St. John the Baptist, that was organized by the quarter communities (cuadrillas) of the town.

Key words: Urban Holidays, Confraternities, Quarter Communities, Modern Age, Soria, St. John the Baptist. 


\section{INTRODUCCIÓN}

Mucho se ha escrito sobre la intervención de los grupos gobernantes en la organización de la fiesta en las ciudades europeas de los siglos bajomedievales y modernos. Con frecuencia se ha explicado como consecuencia del fuerte interés que dichos grupos mostraron por utilizar la fiesta como instrumento de propaganda, legitimación y reforzamiento de la cohesión de la comunidad urbana, que en última instancia sirviese a la preservación de su posición de dominio (Ladero 2004; Burke 1978). Las ciudades del centro y norte de Italia han constituido el ámbito privilegiado para el análisis en profundidad de esta problemática, pues no en vano en ellas fue donde mayor desarrollo alcanzó el modelo de gobierno autónomo basado en el afianzamiento del concepto de comunidad cívica o "república». Destacan algunas monografías dedicadas a casos paradigmáticos como los de Florencia o Venecia (Casini 1996, Texler 1980 y Muir 1981), además de otros estudios en los que se aborda el análisis de varias ciudades desde una perspectiva global (Rogge 2003, Peyer 1955 y Decroisette y Plaisance 1993). Pero también en otros ámbitos de la Europa Occidental donde, sin llegar a las cotas alcanzadas en Italia, las ciudades disfrutaron igualmente de amplios márgenes de autonomía, como es el caso de muchas de las del Imperio romano-germánico, se han acometido estudios en esta línea, que resaltan la utilización de las celebraciones festivas por los grupos gobernantes urbanos para reforzar su posición de dominio (Rogge 2003, Löther 1999, y Schwerhoff 1994).

En los reinos hispánicos el temprano fortalecimiento de la Monarquía, más pronunciado en la Corona de Castilla, dejó menos margen a las ciudades para desarrollarse como ámbitos autónomos para el ejercicio del poder. Esta circunstancia tuvo su particular traducción en el perfil que adoptaron en ellas las celebraciones festivas durante los períodos bajomedieval y moderno, al estar con frecuencia volcadas hacia la exaltación del poder monárquico, para lo que no cabe encontrar parangón en las ciudades italianas o en las del Imperio. En las investigaciones sobre la fiesta en los reinos hispanos bajomedievales, al igual que se ha hecho en Francia, se ha prestado, por consiguiente, bastante más atención a las que tenían un carácter de exaltación de la Monarquía, tales como las organizadas en torno a las entradas reales en las ciudades (Massip 2003). No obstante, también en las ciudades hispanas los grupos gobernantes locales mostraron un fuerte interés por utilizar las celebraciones festivas como mecanismo para reforzar su posición de dominio en el ámbito urbano. Lo han demostrado numerosas monografías que en los últimos años han analizado el papel que los órganos de gobierno concejil desempeñaron en la organización de las fiestas en las ciudades bajomedievales y altomodernas, muy en particular en la del Corpus Christi (Narbona 2003, Beceiro 2009, Martín Cea 1998, Fernández Juárez y Martínez Gil 2002 y Lorenzo Pinar 2010).

El estudio de la fiesta en el marco urbano no puede reducirse, sin embargo, a esta perspectiva, que pone el énfasis en su utilización por parte de los gobernantes como instrumento de control político del conjunto de la población. Por el contrario, son muchas las evidencias que prueban que en las sociedades urbanas preindustriales, al margen de las celebraciones festivas desarrolladas bajo la directa supervisión y control de la autoridad concejil, ya actuase ésta por propia iniciativa o como mera correa de transmisión de la Monarquía, también se organizaron otro tipo de celebra- 
ciones desde otras instancias, que persiguieron otros objetivos, tales como el reforzamiento de los lazos de solidaridad entre los miembros de una determinada comunidad. Es decir, que, junto a las fiestas que tenían un marcado carácter de exaltación institucional, y eran organizadas desde arriba por las autoridades locales, también proliferaron otras que surgían desde la base de forma más espontánea y que trataban de dar respuesta a las más profundas necesidades de socialización y confraternización de la comunidad urbana, o de algún sector de la misma.

A este perfil responden muchas de las fiestas organizadas por las numerosas cofradías que a partir de los siglos medievales proliferaron a lo largo y ancho del continente europeo (Vincent 1994). Pero también otras formas de asociación con notable arraigo en las sociedades urbanas se comprometieron en la organización de este género de fiestas. Entre ellas cabe destacar las constituidas sobre la base de los vínculos políticos creados por razón de la vecindad. En las ciudades de la Corona de Castilla se las conoció con el nombre de "collaciones", parroquias o cuadrillas, las cuales constituyeron los marcos básicos a través de los que se canalizó la participación en la vida política local de la población pechera, excluida desde el siglo XIV de los principales órganos de gobierno, controlados por miembros del estamento hidalgo que acapararon las regidurías.

Ciertamente, no en todas las ciudades estas instituciones alcanzaron similar grado de desarrollo, sino que sólo en unas pocas lograron la plena madurez a partir del período bajomedieval, manteniéndola hasta el fin del Antiguo Régimen. Entre ellas cabe destacar, dentro del privilegiado grupo de las que disfrutaban del derecho de enviar procuradores a Cortes, la de Soria, donde las cuadrillas mostraron un notable grado de vitalidad desde el siglo XV al XVIII, y el Común de pecheros disfrutó del derecho a nombrar cada año un procurador general que le representase en el ayuntamiento con voz y voto (Diago 2004 y 2008).

Esta notable madurez alcanzada por las cuadrillas como marco básico de asociación de la población pechera en Soria se reflejó también en el papel que las mismas asumieron en la fiesta denominada de la Boda de Santa María. Entre los múltiples rasgos singulares de dicha fiesta, figura, en efecto, el hecho de que fue organizada por las referidas cuadrillas en lugar de por la autoridad concejil. De ahí que la hayamos elegido como objeto de estudio de la presente monografía, en la que, además, trataremos de poner de manifiesto algunos paralelismos entre la misma y las fiestas organizadas en la propia ciudad de Soria por diversas cofradías durante la Edad Moderna, con el objetivo de comprobar hasta qué punto todas ellas obedecieron a un mismo patrón, diferente del que caracterizaba a las instituidas por la autoridad concejil, con frecuencia siguiendo directrices marcadas por la Monarquía y la Iglesia. Pretendemos contribuir así a profundizar en la percepción del carácter multifacético de la fiesta, llamando la atención sobre su importancia como elemento integrante de la cultura popular. Al mismo tiempo, el ejemplo escogido nos ha parecido interesante para reflexionar en torno a la cuestión de la permanencia en el mundo industrializado actual de manifestaciones residuales de dicha cultura popular, que dejó de funcionar como sistema cohesionado hace siglos, como consecuencia de la irrupción de la industrialización en las sociedades occidentales (Batjin 1971). 


\section{LA BODA DE SANTA MARÍA: UNA FIESTA SINGULAR DE LA CIUDAD DE SORIA}

Las que hoy se denominan fiestas de San Juan o de la Madre de Dios, constituyen uno de los elementos más singulares del patrimonio histórico, cultural y antropológico de la ciudad de Soria, que ha hecho posible que una institución del Antiguo Régimen, como son las cuadrillas del Común de pecheros, hayan continuado en funcionamiento en el marco de las sociedades liberales a partir del siglo XIX para asegurar que se siga celebrando una fiesta que puede considerarse prototípica de la tradicional cultura propia del mundo preindustrial (Diago 2008). En el siglo XV esta singular celebración todavía la encontramos identificada con la denominación de fiesta de la Boda de Santa María, que también se utilizó en esta misma época para referirse a las fiestas de lugares muy próximos a Soria, como su aldea Vinuesa, donde, no obstante, se celebraba el día de la Asunción de la Virgen (15 de agosto), y de otros bastante más distantes dentro de la Corona de Castilla, como Cea (León) o Talavera de la Reina (Álvarez García 1955: 9-10, Ladero 2004: 59-65)․․ El término "boda", sin embargo, pronto cayó en desuso en Soria, consolidándose en su lugar en el transcurso del siglo XVI la denominación de fiesta de Nuestra Señora.

La documentación conservada atestigua que esta fiesta ya constituía un episodio destacado de la vida social en la ciudad del Duero durante la segunda mitad del siglo XV, repitiéndose todos los años el primer domingo después del día de San Juan Bautista (24 de junio) ${ }^{2}$. Y en esa misma fecha se ha venido celebrando hasta la actualidad, con pocas interrupciones ${ }^{3}$. En el pasado, no obstante, ese mismo domingo era una fecha señalada con evidente popularidad en la comarca soriana, pues nos consta que también se conmemoraba en las villas de Almazán y San Pedro Manrique.

La documentación de los primeros años del siglo XVI da cumplido testimonio de la celebración en Almazán ese domingo de una fiesta en honor de Nuestra Señora, que presenta evidentes paralelismos con la que tenía por escenario ese mismo día la ciudad de Soria. En ambos casos se ofrecía una multitudinaria comida de "caridad", después de una procesión y una misa, sacrificándose para el consumo de los asistentes un importante número de novillos ${ }^{4}$.

${ }^{1}$ En Vinuesa se sigue conmemorando en la actualidad la fiesta de la Asunción, aunque con actos festivos distintos a los de fines del Medievo. En Cea (León) está documentada en el año 1487, y en Talavera de la Reina se celebraban los esponsales de la Virgen con San José en la Pascua de Resurrección.

${ }^{2}$ Un testimonio claro en este sentido lo proporciona una provisión de los Reyes Católicos al concejo de Soria, fechada en Zaragoza, 8-II-1488, en la que se indica que la aljama de los judíos les había informado que "esa dicha çibdad acostumbra faser una fiesta el primero domingo despues de San Juan, la qual llamays la boda de Santa Maria, en la qual fiesta diz que matan çiertos nobillos e comen e beven en ella". Publica la provisión Suárez Fernández (1964: 296-297).

3 Aunque hoy se conocen estas fiestas en Soria con el desorientador nombre de "fiestas de San Juan", siguen celebrándose el primer domingo después de la fiesta del Bautista, que ahora se llama Domingo de Calderas, por la procesión con calderas, aderezadas con carne guisada de toro, que protagonizan las doce cuadrillas de la ciudad, y que en lo sustancial responde a las mismas características que la de los siglos XV y XVI, aunque ha perdido mucho de su contenido religioso y algunos de sus ritos más singulares.

${ }^{4}$ Informaciones sobre la fiesta de Almazán en los libros de actas del concejo, en el archivo municipal de la villa. Sobre la procesión, previa a la comida, ver también Archivo Chancillería de Valladolid, Registro de Ejecutorias, 892-23 (VII-1557). 
Por lo que respecta a San Pedro Manrique, una relación manuscrita que escribió a finales del siglo XVIII un cura de esta villa nos informa de que ese mismo domingo tenía lugar allí una singular procesión en honor a la Virgen, en el transcurso de la cual se sucedían varios actos cargados de simbolismo, que ofrecen interesantes paralelos con ciertas celebraciones festivas de otras poblaciones castellanas, y con la de Soria en particular. Cuando llegaba la procesión a la iglesia de San Miguel, se incorporaban a ella, colocándose por delante de la imagen de la Virgen, tres mozos bien vestidos de militar, de los cuales el que iba en medio llevaba un traje negro y un ramo lleno de roscos, y tres doncellas vistosamente ataviadas, que portaban tres cestaños de pan de color amarillo. Más tarde se celebraba misa solemne, tras la cual los oficiales de la justicia pasaban a besar las manos del preste, los tres mozos y las doncellas. Concluido el acto, el mozo del medio arrojaba el ramo y los chicos le quitaban los roscos (Álvarez García 1995: 13).

No sabemos de cuándo puede datar esta singular celebración que, con algunas de sus características más peculiares, como el desfile de las doncellas portadoras de canastos, a las que se llama Móndidas, pervive en la actualidad, aunque en fecha distinta, pues ahora tiene lugar el propio día 24 de junio, después de que la noche anterior, la celebérrima Noche de San Juan, los mozos del pueblo hayan sido protagonistas del singular rito del paso del fuego ${ }^{5}$. Lo que nos interesa aquí recalcar, en cualquier caso, es que la procesión que en el pasado se celebraba en San Pedro Manrique el primer domingo después de San Juan ofrece claros paralelismos con la que ese mismo día ha venido celebrándose desde época bajomedieval en Soria. El más notable es la participación en ambas procesiones de mozos portadores de un ramo o "argujuelo" ${ }^{6}$, que constituye un elemento cargado de simbolismo, presente en celebraciones de muy diverso signo en la Castilla preindustrial, incluso en algunas de marcado carácter político. Así lo testimonia, por ejemplo, el caso de Babia de Suso, en la provincia de León, donde a principios del siglo XVI se observaba la costumbre de elegir el día de San Juan jueces, a los que se había usado desde antiguo entregar "cierto ramo"

No vamos a profundizar en la interpretación del significado de estos paralelismos, que también cabe establecer con otras celebraciones registradas en lugares de Castilla, como las Mondas de Talavera de la Reina (Caro Baroja 1974: 31-51). Sólo nos ha interesado llamar la atención sobre ellos para encuadrar en su contexto la fiesta de Soria. Al mismo tiempo, también ha sido nuestra intención demostrar que, pese a que en muchos aspectos esta última puede considerarse única en el panorama de la España actual, presenta muchos rasgos en común con otras celebraciones que tuvieron por

\footnotetext{
${ }^{5}$ Aunque este paso del fuego constituye hoy día unos de los principales atractivos turísticos de estas fiestas, para el que se han buscado precedentes hasta en tiempos prehistóricos, no hay pruebas de su celebración hasta fechas muy recientes, en el siglo XX (Álvarez García 1995, Díaz Viana y Martínez Laseca 1992:181-196).

${ }^{6}$ En el caso de Soria no era un solo mozo sino que cada cuadrilla acudía a la procesión con la imagen del santo titular, precedida por un mozo que llevaba alzado un "argujuelo".

${ }^{7}$ Archivo General de Simancas, Registro General del Sello, VI-1523. Provisión al juez de residencia o corregidor de León. Se había denunciado que "sobre el dar el dicho ramo el día de San Juan se esperan muchos ruidos, escándalos y muertes de hombres entre las partes", en concreto entre el concejo y vecinos de Babia, y Pedro de Quiñones, vecino de León.
} 
escenario en el pasado el entorno soriano, ya desaparecidas, como las de Almazán, o que perviven con radicales transformaciones, como las de San Pedro Manrique o Vinuesa.

\section{ELEMENTOS SINGULARES EN LA ORGANIZACIÓN DE LA FIESTA DE LA BODA DE SANTA MARÍA}

Entre las muchas que tuvieron por escenario la ciudad de Soria en los siglos bajomedievales y modernos (Diago, 2003), la fiesta de Nuestra Señora fue la única, si exceptuamos las organizadas por las cofradías, que escapó al control y la planificación de las autoridades civiles y eclesiásticas. Ciertamente hubo algunos intentos por parte de éstas de someterla a su directa supervisión. Cabe destacar en concreto el del año 1536, fecha de promulgación de unas ordenanzas, que llegaron a ser confirmadas por la propia emperatriz Isabel, a las que nos referiremos más adelante. Pero tales intentos fracasaron, y la organización de la fiesta permaneció en manos de las cuadrillas hasta el fin del Antiguo Régimen, preservándose de este modo uno de los elementos que más contribuyeron a conformar su singularidad.

La cuadrilla fue, en efecto, entre los siglos XV y XVI la célula fundamental en torno a la que giró todo el proceso de la celebración. Se trata de una institución de agrupación de la población pechera que, según todos los indicios, debió consolidarse en Soria en el transcurso del siglo XIV, en sustitución de las antiguas "collaciones". Servía para canalizar la participación del estamento pechero en la vida política local. Así, cada año, los vecinos pecheros de cada cuadrilla elegían un representante, el jurado, y, en una segunda fase, los jurados de todas las cuadrillas procedían a designar entre ellos un procurador general del Común, que durante un año estaba al frente del gobierno del estamento pechero y lo representaba en el ayuntamiento de concejo (Diago 2004).

El jurado era la máxima autoridad de la cuadrilla y, para el desempeño de sus tareas, estaba auxiliado por otros cuatro oficiales, a los que, por razón de su número, se identificó con el nombre de cuatros. No obstante, dada la importancia que las cuadrillas asignaron a la organización de la fiesta de Nuestra Señora, se impuso la costumbre de designar también cada año otro oficial con la exclusiva responsabilidad de asumir el desempeño de esta tarea, al cual se conoció con el nombre de mayordomo ${ }^{8}$.

Podemos conocer con relativo detalle las funciones que debía asumir este oficial a partir del juramento prestado por algunos de los que desempeñaron el cargo en el momento de ser elegidos. Básicamente se comprometían a comprar un novillo "a contento" del jurado y de los cuatros. Después, el viernes llamado "de los novillos", tenían obligación de dar de comer a los cuatros, "como es costumbre para echar los oficios", y al domingo siguiente debían organizar una comida con carne de carnero,

\footnotetext{
${ }^{8}$ Entre otros muchos, un interesante ejemplo de designación de "mayordomos" con la misión de organizar una fiesta lo encontramos en la villa granadina de Aldeire, donde los vecinos cada año designaban dos por sorteo, el 24 de abril, para que al año siguiente organizasen la comida de caridad que se celebraba por voto del pueblo el día de San Marcos, 25 de abril (Rivas 1983).
} 
tocino, las raciones del novillo, pan y vino. Pero a estas prestaciones básicas, se fueron añadiendo otras muchas.

Interesa destacar que el desempeño del oficio de mayordomo fue concebido como un "servicio" prestado a la cuadrilla a fin de que se pudiese celebrar la fiesta, y, por consiguiente, a la propia Virgen María, en honor a la cual se organizaba la misma. El concepto de "servicio" se repite reiteradamente en la documentación de las cuadrillas de los siglos XVI y XVII. Y no se trata de mera retórica, puesto que muchos indicios invitan a concluir que el desempeño de este oficio representaba una pesada carga, que exigía importantes inversiones en tiempo y dinero, sin otra compensación que la del honor que pudiese conllevar el haber prestado adecuadamente, a los convecinos y a la Virgen, el servicio que de uno se esperaba.

Hasta tal punto el ser mayordomo representaba una carga que nos consta que fueron muchos los vecinos que prefirieron entregar una cantidad de dinero a su cuadrilla, a cambio de que les eximiese del cargo. Los testimonios de esta práctica son numerosos, sobre todo durante el siglo XVII, quizás en parte porque la documentación conservada es más abundante en esta centuria, aunque probablemente también porque entonces la práctica se fue haciendo cada vez más frecuente.

Las cantidades por las que se daba por servidos a los vecinos variaron de forma apreciable, de modo que podemos encontrarnos que en un mismo ejercicio en una misma cuadrilla unos entregasen más del doble que otros ${ }^{9}$. A este respecto conviene tener en cuenta que, aunque las cuadrillas estaban controladas por los pecheros, a efectos de la organización de la fiesta incorporaban también a los hidalgos que residían en el espacio urbano asignado a cada una de ellas; de ahí que la obligación de servir el oficio de mayordomo alcanzase igualmente a éstos. Así nos lo confirma, por ejemplo, una noticia sobre el pago de 550 reales por Don Íñigo López de Salcedo a la cuadrilla del Collado, para hacer la fiesta de Nuestra Señora, "por que se le diese por servido del nombramiento que le estaba hecho" ${ }^{10}$. Se trata de una cantidad bastante elevada, acorde con la elevada fortuna del caballero que la abonó. Por ello entendemos que las enormes diferencias existentes en las aportaciones efectuadas por los vecinos a cambio de que se les diese por servido el oficio de mayordomo simplemente tradujeron las aún mayores diferencias existentes entre sus niveles de riqueza, en una sociedad muy desigual, como fue la soriana en estos siglos.

En cualquier caso, el mero hecho de que se estuviese dispuesto a pagar dinero para evitar el desempeño de un cargo resulta chocante en el contexto de la sociedad castellana de los siglos XVI y XVII, en la que alcanzó extraordinaria difusión la práctica inversa, es decir, pagar elevadas cantidades de dinero para adquirir los numerosos oficios de gobierno local que fueron puestos a la venta por una Monarquía con un voraz apetito recaudatorio. Esta constatación nos confirma hasta qué punto en la

\footnotetext{
9 La cuadrilla de San Esteban en 1596 acordó dar por servido a Juan Martínez, carnicero, a cambio de 200 reales, y a Francisco López a cambio de 100. En las cuentas al jurado de la cuadrilla de San Esteban correspondientes al período de 1641 a 1649 se registran las siguientes cantidades entregadas por vecinos a los que se dio por servido el oficio de mayordomo: Diego de Caravantes 250 reales; Francisco La Vega 250; Jerónimo Martínez, cirujano, 176; Juan de Santisteban 150; Juan Álvarez, 100; Gregorio de Vera, platero, 100 reales; Juan de Vera, 80, y Miguel Ducha 70. Libro de cuadrilla, fol. 159.

${ }^{10}$ AHPS, PN. 741-1203-24. Cuentas de la cuadrilla del Collado del ejercicio 1652-1653.
} 
organización de la fiesta de Nuestra Señora primaba el móvil de la potenciación de los vínculos de solidaridad entre los vecinos, en el marco de sus cuadrillas. Existía una responsabilidad del individuo hacia el colectivo, que es la que justificaba la exigencia del desempeño del oficio de mayordomo; nadie se podía sustraer a ella. Pero si finalmente se abrió la puerta a las conmutaciones por dinero fue probablemente porque de esta manera se podía contribuir a paliar la mala situación financiera de las cuadrillas, y evitar al mismo tiempo tener que someter a los vecinos a una excesiva presión fiscal para garantizar la continuidad de la fiesta.

A este respecto, cabe advertir que esta misma concepción del desempeño de los oficios como un servicio que se debía prestar a la comunidad, que detectamos en las cuadrillas por lo que respecta al oficio de mayordomo y a otros relacionados con la organización de la fiesta, como los de servidor de damas y sacador de mozas, también resulta perceptible en diversas cofradías, que recurrieron al expediente de dar por servido el oficio de preboste a cofrades dispuestos a ofrecer a cambio una compensación económica ${ }^{11}$.

\section{LA FINANCIACIÓN DE LA FIESTA}

Entre los factores que confieren singularidad a la fiesta de Nuestra Señora en Soria en relación a otras organizadas por el concejo en esta misma ciudad, destaca su régimen de financiación. El concejo, en efecto, no hizo ninguna aportación destinada a cubrir los gastos generados a lo largo de todo el período analizado, a diferencia de lo que ocurre en la actualidad, y en claro contraste con su forma de proceder en otras celebraciones, como el Corpus Christi, las corridas de toros del día de San Juan Bautista, Santiago y Santa María de Agosto, o las fiestas de San Saturio, patrón de la ciudad, que comenzaron a celebrarse con creciente solemnidad a partir del siglo XVII. Para todas ellas, el concejo, que designaba cada año entre sus oficiales dos comisarios encargados de su organización, aportaba fondos, mediante libramientos en algunas de sus rentas. Por contraste, la organización y financiación de la fiesta de Nuestra Señora fue asumida de forma exclusiva por las cuadrillas, sin intervención de ninguna otra instancia, laica o eclesiástica ${ }^{12}$.

Para este efecto las cuadrillas disponían de algunos modestos recursos propios, entre los que destacaba la renta en cereal que percibían por su tajón en la dehesa de Valonsadero, desde que la Chancillería de Valladolid autorizó la labranza en una parte de la misma por una ejecutoria de 1512. Se trataba de un ingreso en especie, que estuvo en el entorno de las 30 medias de trigo anuales. Una parte de este trigo era puesto por la cuadrilla a disposición del mayordomo para que lo destinase al

\footnotetext{
${ }^{11}$ El cabildo de los Heros, que agrupaba a los labradores de la ciudad, en su asamblea general del 8 de septiembre de 1578 acordó dar por libres a tres labradores con carácter vitalicio de la obligación de desempeñar el oficio de preboste, a cambio de una compensación, fijada respectivamente en 100 reales, 6 ducados y una vaca. AHPS, PN, 143-300-87, 87v y 88.

${ }^{12}$ Cuando Isabel Beceiro afirma que en Soria no está registrada ninguna institución que participe en los gastos y preparativos de los festejos salvo el concejo, pasa por alto la notable implicación de las cuadrillas en la organización y financiación de la fiesta de la Boda de Santa María (Beceiro 2009: 204).
} 
consumo de los que asistiesen a la comida de caridad del domingo de la fiesta de Nuestra Señora. Pero en otras ocasiones el trigo, que solía cobrarse a mediados de agosto, era prestado a vecinos necesitados de la ciudad, que se comprometían a devolverlo en forma de pan cocido las vísperas de la fiesta, para que pudiese ser consumido en la referida comida ${ }^{13}$. El resto del trigo solía venderse, para disponer de dinero con el que atender las necesidades de la cuadrilla, y ayudar a cubrir los gastos generados por la fiesta sin sobrecargar al mayordomo.

Las cuadrillas tenían también a su disposición algunas otras fuentes de ingresos de carácter irregular, entre las que cabe destacar las cantidades de dinero abonadas por los vecinos a cambio de que se les diese por servido el oficio de mayordomo. Pero este capítulo experimentó enormes fluctuaciones y estuvo totalmente ausente en un gran número de ejercicios. También muy fluctuantes fueron las cantidades ingresadas por otros conceptos, como las ventas de los despojos del toro y los carneros sacrificados para el consumo de carne durante la fiesta.

Con ayuda de las aportaciones efectuadas por la cuadrilla, los mayordomos tenían que hacer frente a un amplio capítulo de gastos ${ }^{14}$. Uno de los principales desembolsos era para la compra del novillo, sin el cual no había fiesta, puesto que uno de sus momentos centrales era el consumo de su carne en la "caridad" del domingo. Y también era costumbre muy arraigada que el viernes anterior, conocido como "viernes de novillos", los vecinos de cada cuadrilla se divirtiesen corriendo el suyo por sus calles, sujetándolo con una maroma que para ello tenía dispuesta la propia cuadrilla ${ }^{15}$. El animal no moría sin embargo en el curso de estas "corridas", sino que nos consta expresamente que para sacrificar al novillo cada cuadrilla contrataba a un matarife profesional, al que se abonaba por su trabajo un pequeño salario, de en torno a los seis reales.

Además del novillo, se compraban carneros y otros productos para consumir tanto en la comida de la caridad como en otros ágapes organizados por la cuadrilla. Pero el "programa festivo" también incorporaba algunas celebraciones que ocasionaban otro tipo de gastos. Entre ellas cabe diferenciar las de carácter religioso de las profanas, aunque con frecuencia unas y otras tendían a confundirse, por ejemplo al introducirse música y danzas en la procesión que se celebraba el domingo a la iglesia del priorato de Nuestra Señora de Mercado, con las imágenes de los santos patronos de las cuadrillas ${ }^{16}$. Las ceremonias religiosas en las que tenían que invertir pequeñas cantidades de dinero, para la compra de cera o para el pago a los clérigos, no se reducían a esta procesión y a la misa que se celebraba a continuación. También tenemos

\footnotetext{
${ }^{13}$ Por ejemplo en 19-1-1684 dos vecinos se obligaron a entregar a la cuadrilla de La Mayor, "el viernes que llaman de los novillos", 5 fanegas de trigo en pan cocido de flor a 14 cuartales cada fanega, por otras tantas que les había prestado la cuadrilla. AHPS, PN, 860-1364-26.

${ }^{14}$ Reconstruimos el capítulo de gastos basándonos en la información aportada por el libro de la cuadrilla de San Esteban, el más antiguo de los conservados en el archivo municipal de Soria.

${ }^{15}$ En las cuentas tomadas al jurado de la cuadrilla del Collado correspondientes al año 1653 figura un gasto de 38 reales por una maroma nueva que se compró, y un ingreso de 22 por la vieja, que se vendió. AHPS, PN, 741-1203.

${ }^{16}$ Se contempló que en esta procesión "yendo y beniendo lleven tamborinos o menestriles o danças o ynbençiones que sean de onbres e non de mugeres por solemnizar la procesión y fiesta" (Diago 2003).
} 
noticia del rezo de una Salve el sábado, y de la celebración de una misa en la iglesia del monasterio hospitalario de San Juan de Duero, "para las damas". Y en el capítulo de los gastos derivados de las diversiones profanas encontramos regularmente pagos a músicos, contratados para amenizar los bailes ${ }^{17}$. Por mucho que se esforzasen el mayordomo y los demás oficiales implicados por gastar con moderación, los gastos fácilmente se disparaban muy por encima de los ingresos. Se generaba de este modo un déficit que, en caso de ser asumido en solitario por el mayordomo, podía resultarle en exceso oneroso ${ }^{18}$. Se evitó por ello cargar sobre este oficial la responsabilidad de cubrir dicho déficit, recurriéndose al expediente de efectuar repartimientos entre todos los vecinos para recaudar el dinero necesario con el que cubrirlo.

El primer testimonio de dicha práctica nos lo proporciona la queja presentada ante los Reyes Católicos por los judíos sorianos en 1488, cuando denunciaron que, desde que habían dejado de vivir apartados en el castillo y habían pasado a residir en los mismos barrios que los cristianos, se les estaba obligando a contribuir junto con ellos en la financiación de la fiesta de la boda de Santa María, y se les cargaban grandes cuantías de maravedíes, "non comiendo ellos en esa dicha fiesta nin aviendo parte della ${ }^{19}$.

Más explícitas son las ordenanzas redactadas en el año 1536, en el preámbulo de las cuales se denunció que hasta aquel momento los mayordomos designados por las cuadrillas, para sufragar los gastos de la fiesta, habían estado efectuando muchos repartimientos de maravedíes entre los vecinos de todos los estados, clérigos y laicos, ricos y pobres ${ }^{20}$. Esto había propiciado que se hiciesen gastos excesivos, que resultaba imperativo atajar. Por ello con estas nuevas ordenanzas se trató de imponer una radical modificación del modelo de financiación de la fiesta, a la vez que se despojaba a ésta de todos los elementos que se consideraba que pervertían su espíritu originario ${ }^{21}$. En concreto, se buscó arrebatar a las cuadrillas el papel central en su organización y financiación que hasta entonces habían asumido, para transferirlo directamente al concejo, lo que en última instancia equivalía a desvirtuar la celebración, privándola de cuanto había en ella de potenciador del espíritu comunitario entre los vecinos. Las ordenanzas

${ }^{17}$ Un gaitero solía tocar a la puerta de la casa del mayordomo, para que los vecinos pudiesen bailar al son de la gaita. Se deduce del acuerdo tomado en 20-V-1601 por la cuadrilla de San Esteban, a raíz de habérsele muerto su esposa al mayordomo. Se reconoció en concreto que "no es razón, por estar recién viudo, tener la gaita y regocijo a su puerta, como la fiesta la requiere». Ver libro de cuadrilla, fol. 101v. En las relaciones de gastos de los mayordomos figuran regularmente pagos efectuados a un juglar o al que tocaba la gaita.

${ }^{18}$ A este problema se enfrentaron los mayordomos que organizaron la fiesta y caridad de San Marcos en la villa granadina de Aldeire, muchos de los cuales quedaron en precaria posición económica después de desempeñar el cargo (Rivas 1983).

19 Según documento publicado por Suárez Fernández (1964: 296-7).

${ }^{20}$ Las ordenanzas se pueden consultar en Archivo Municipal de Soria, documentos singulares, $\mathrm{n}^{\mathrm{o}} .21$.

${ }^{21}$ A estos elementos añadidos se refería el preámbulo de las ordenanzas cuando lamentaba que «en la orden de las procesyones no se tenia aquella reverençia e solemnidad que se requeria y se azia de noche y de dia otras muchas cosas y cometian pecados publicos". Para acabar con ellos, dispusieron que en adelante ninguna cuadrilla hiciesen "bailas ni danzas por las calles", y que la fiesta ocupase exclusivamente el domingo y no se extendiese al viernes y sábado anteriores, y lunes siguiente, como estaba ocurriendo. 
dispusieron, en concreto, que en adelante las cuadrillas dejasen de designar todos los años un mayordomo que se hiciese cargo de la organización de la fiesta. También les privaron de su función de comprar cada una su novillo, para correrlo por las calles y luego sacrificarlo, disponiendo que en adelante fuese el propio concejo el que cada año se encargase de comprar los que fuese menester para que se gastasen y diesen cocidos y hechos raciones en la caridad que se daba en el Campo de San Francisco. Y, por fin, también quedó terminantemente prohibido a las cuadrillas efectuar en adelante derramas entre sus vecinos para sufragar gastos relacionados con la fiesta. Como procedimiento alternativo dispusieron que fuese el propio concejo quien se hiciese cargo de cobrar la renta en cereal abonada por los arrendatarios de los tajones de Valonsadero, con el argumento de que dicha renta pertenecía a todos los vecinos, de los tres estados. Dicho cereal debería ser destinado a cubrir los gastos de la fiesta y, en el caso de no resultar suficiente, se financiaría el resto con cargo a los propios de la ciudad. Todo para evitar que en el futuro se continuasen efectuando los repartimientos que, a juicio de los redactores de las ordenanzas, resultaban en exceso gravosos para los pobres de la ciudad.

Ni que decir tiene que, de haberse llegado a aplicar este modelo de organización y financiación, la naturaleza de la fiesta de Nuestra Señora habría quedado radicalmente transformada, perdiendo todo su carácter espontáneo y popular, para convertirse en una celebración más al servicio de la legitimación del orden jerárquico establecido. Pero, aunque la documentación conservada no permite conocer en detalle lo que ocurrió después de la ratificación de estas ordenanzas por la emperatriz Isabel, ni si hubo algún intento de llegar a aplicarlas, es seguro que, en caso de haberlo habido, no prosperó ${ }^{22}$. Todo indica, por el contrario, que la fiesta continuó organizándose conforme al modelo tradicional, es decir, sin intervención del concejo y mediante la designación por cada cuadrilla de un mayordomo, que se hacía cargo de la compra del novillo.

Una prueba la proporcionan unas ordenanzas que en 1544 aprobó para su uso interno la cuadrilla de San Esteban, una de las diecieseis en que se distribuía la población pechera soriana en el siglo XVI, que fueron además confirmadas por la autoridad concejil. Dichas ordenanzas se centraron en la regulación de algunos aspectos controvertidos de la organización de la fiesta de Nuestra Señora y contradicen punto por punto todo lo dispuesto en las de 1536, a la vez que confirman que los mayordomos continuaban efectuando derramas entre los vecinos de la cuadrilla para sufragar los gastos de la fiesta ${ }^{23}$.

Podemos conocer más detalles sobre estos repartimientos gracias al libro de cuentas y acuerdo de esta misma cuadrilla, que da cumplida cuenta de muchos de los realizados a lo largo del siglo XVI. La decisión de realizar la derrama se tomaba el día siguiente a la finalización de la fiesta, cuando los contadores designados al efecto tomaban cuenta de ingresos y gastos al mayordomo saliente. Una vez averiguada la

\footnotetext{
${ }^{22}$ Sabemos que en 1540 el concejo de Soria otorgó otras nuevas ordenanzas, que tampoco hay constancia de que llegasen a ser aplicadas. Según Martín de Marco (1999: 49), entre 1536 y 1540 no hubo fiestas, pero no aporta prueba documental para demostrarlo.

${ }^{23}$ Estas ordenanzas de la cuadrilla de San Esteban en el libro que se conserva en el Archivo Municipal de Soria, del que también tomamos el resto de noticias relativas a ella.
} 
cantidad que éste había alcanzado, se decidía su reparto por derrama entre todos los vecinos, y acto seguido el mayordomo, acompañado de seis personas designadas al efecto, iniciaba el recorrido por todas las casas de la cuadrilla para cobrar las cantidades que hubiesen sido repartidas a cada vecino ${ }^{24}$. Los criterios seguidos para realizar los repartimientos no fueron en todas las ocasiones idénticos, sino que variaron de unos años a otros, aunque en lo substancial todos siguieron un patrón muy simple. Apenas se establecieron gradaciones en función del patrimonio o nivel de ingresos, sino que básicamente se trató de un impuesto de capitación, en el que todas las familias aportaban idéntica cuantía, con la única excepción de las viudas y los pobres, que solían pagar mucho menos. Por otra parte, el esfuerzo financiero exigido a los vecinos también varió de forma apreciable de unos años a otros, porque hubo oscilaciones en el número de escoteros, y porque el balance entre ingresos y gastos también experimentó fuertes fluctuaciones. Los repartimientos entre vecinos o escoteros no se realizaron, sin embargo, de forma sistemática todos los años. En determinados ejercicios las cuadrillas podían decidir en asamblea que ese año no se pagase escote ninguno. Conforme avanzó el siglo XVII se tendió, no obstante, con creciente frecuencia a prescindir de ellos, quizás como consecuencia del deterioro de la situación económica. A cambio se fue imponiendo la práctica de efectuar "Socorros" al mayordomo, para ayudarle a financiar los gastos de la fiesta. Pero como estos "socorros" solían ser muy cortos, es probable que los mayordomos tuviesen que aportar cada vez más dinero de su propio bolsillo. Quizás por ello en el transcurso del siglo XVII se multiplicaron los acuerdos de las cuadrillas con algunos de sus vecinos para darles por servido el oficio a cambio de la entrega de una cantidad de dinero. Al mismo tiempo muchas cuadrillas, para hacer más soportable la carga financiera que llegó a representar el desempeño del oficio de mayordomo, decidieron nombrar dos en lugar de uno $^{25}$.

Recapitulando, aunque los mecanismos de financiación de la fiesta de Nuestra Señora no se mantuvieron inalterados a lo largo del período moderno, todos ellos, si exceptuamos el previsto en el radical intento de reforma de 1536, se basaron en el principio de la contribución solidaria de todos los vecinos, dispuestos a sacrificarse por el bien de la comunidad. Ni que decir tiene que siempre hubo unos que tuvieron que aportar más que otros, y que de esta circunstancia a veces se derivaron fuertes tensiones, e incluso abiertos conflictos, en los que tuvo que intervenir como árbitro el corregidor. Pero las cuadrillas supieron superar estas tensiones, a veces renunciando a ciertas celebraciones porque el deterioro de la situación económica así lo requería, para de este modo preservar su autonomía y evitar que la autoridad municipal se hiciese con el control de la organización de su fiesta, como lo había intentado en 1536.

\footnotetext{
${ }^{24}$ Las ordenanzas disponen literalmente que han de ir de casa en casa, "y no pasen de ninguna casa sin que el vecino de ella pague luego el dicho repartimiento que le fuese echado en dineros, o dé prendas bastantes".

${ }^{25}$ La cuadrilla de San Esteban en su reunión de 3-5-1696, en que había de decidir sobre el socorro que se había de dar a los dos mayordomos, acordó que "respecto de ser dos los que sirven y considerando los pocos medios de la cuadrilla" sólo se les entregasen 100 reales y el pan cocido. Libro de cuadrilla, fol. 315.
} 


\section{CARIDAD Y COMIDAS COMUNITARIAS EN LA FIESTA DE NUESTRA SEÑORA}

El acto central en torno al que giraba la fiesta de Nuestra Señora era la comida de caridad que se ofrecía el domingo, después de la procesión a la iglesia del priorato de Nuestra Señora de Mercado, y que tenía por escenario el Campo de San Francisco, extramuros de la ciudad. Así lo hicieron ver los redactores de las ordenanzas de 1536, cuando en el preámbulo a las mismas declararon que: "se dio siempre una caridad de pan y vino y carne de vaca cocida a las personas que la quisieren recibir, ansi de los que venian de fuera desta cibdad como a vecinos della", añadiéndose que todo esto "fue ynventado para dar a los pobres". Conscientes de este hecho, los promotores de dichas ordenanzas centraron su atención en asegurar que la referida comida de caridad se continuase celebrando en el futuro, aunque despojando a las cuadrillas del papel que hasta entonces habían desempeñado en su organización, y con el decidido propósito de eliminar el resto de celebraciones, que con sus excesos e innovaciones habían desvirtuado a su juicio el sentido originario de la fiesta, hasta el punto de que se llegaban a cometer "pecados públicos" en el transcurso de la mis$\mathrm{ma}^{26}$.

Dejar reducida la fiesta a la procesión, la misa solemne y la comida de caridad, celebrada inmediatamente después, como era la pretensión de los reformadores de 1536, no resultaba del agrado de los pecheros sorianos. Y tal debió ser la resistencia ofrecida por ellos, que, como hemos visto, los afanes reformistas fracasaron estrepitosamente, de modo que en adelante las celebraciones de carácter solidario continuaron coexistiendo con otras muchas diversiones de carácter profano, sin más objeto que proporcionar satisfacción a los afanes lúdicos de la población.

Pero el carácter esencialmente solidario de la fiesta se preservó por la prioridad que en todo momento se continuó dando a la comida de la caridad del domingo como acto central, abierto a la participación de propios y extraños. Así en las ya mencionadas ordenanzas de la cuadrilla de San Esteban de 1544 se dedica amplio espacio a disponer lo que el mayordomo debía hacer en relación a dicha comida. En concreto se le exigía que preparase 330 raciones de pan blanco y bueno, haciendo de cada cuarta de pan tres raciones, más otras 330 raciones de carne, y seis cántaras de vino. Todo esto había de llevarlo al Campo de San Francisco para que allí se consumiese, y no hubiese falta. Para las raciones de carne se utilizaba la del novillo que era sacrificado para la ocasión, pero también se consumía abundante carne de carnero, y toda ella se guisaba en una caldera en el propio campo por una persona contratada al efecto ${ }^{27}$. Las ordenanzas dispusieron, por otra parte, que el mayordomo debería dar a los servidores de damas que fuesen nombrados dos piezas de vaca, una cántara de

\footnotetext{
${ }^{26}$ En el preámbulo a la confirmación de las ordenanzas por el obispo Pedro González Manso, en Burgo de Osma, 28-4-1536, éste declaró que en la visita pastoral que había efectuado a la ciudad de Soria el año anterior se había informado de que en ésta se celebraba cada año una fiesta de Nuestra Señora el primer domingo después de San Juan, en la que se hacian gastos excesivos, "y en la orden de las procesyones no se tenia aquella reverençia e solemnidad que se requeria y se azia de noche y de dia otras muchas cosas y cometian pecados publicos".

${ }^{27}$ En las cuentas que dio el mayordomo de la cuadrilla de San Esteban de 30-6-1608, incluyó 2 reales "del alquiler de la caldera para el campo", y 3 reales "a quien guisó la caldera en el campo".
} 
vino, ocho cuartales de pan, y 10 libras de guindas, todo ello para el consumo de las señoras que fuesen al campo a acompañar a la mayordoma el domingo. Y para el consumo de las mozas debería dar una pieza de vaca, media cántara de vino, 4 cuartales de pan y 4 libras de guindas, habiéndolo de entregar en este caso al "sacador de las mozas". Estas disposiciones no resultan de fácil interpretación, pero de ellas parece deducirse que, al margen de la comida de caridad, probablemente antes de la misma, por la mañana, las mujeres de la cuadrilla celebraban un almuerzo en que los servidores de las damas y el sacador de mozas las agasajaban, invitándolas a pan, vino y carne de vaca.

Las comidas festivas conocidas con el nombre de "caridad" estuvieron muy extendidas en la Castilla del Antiguo Régimen ${ }^{28}$, y algunas de ellas todavía continúan celebrándose en la actualidad. Es el caso de la que tiene lugar en la ermita de Lomos de Orio, en término de Villoslada de Cameros (La Rioja), el primer domingo de julio, o, en un ámbito mucho más alejado del soriano, la que tiene por escenario la villa granadina de Aldeire en la fiesta de San Marcos (Rivas 1983). Los ejemplos se podrían multiplicar, pero, al margen del rasgo común del reparto de alimentos a todas las personas presentes en la celebración, son muchas las diferencias que separan a unas de otras. Con frecuencia se trata de celebraciones que tienen su origen en el siglo XVI, por votos hechos a santos u otros intercesores sobrenaturales en agradecimiento por favores recibidos, o para conseguir su protección frente a determinadas amenazas de la naturaleza. La "caridad" de las cuadrillas de Soria por el contrario es más antigua, pues ya se encontraba plenamente consolidada a fines del siglo XV, no consta que surgiese como consecuencia de un "voto", y, al margen de las peculiaridades de su régimen de financiación, ofrece como principal singularidad el destacado papel que en ella desempeñaban las calderas en las que se guisaba la carne de un toro que había sido sacrificado para la ocasión. Esta carne era el elemento central de la celebración, que, por el contrario, estaba ausente de las otras "caridades" en que el "pan cocido" ocupaba su lugar protagonista.

Además de la "caridad" del domingo las cuadrillas sorianas organizaron algunas otras comidas comunitarias que ampliaron el calendario festivo varios días más. Se diferenciaron, no obstante, de aquélla en que en ellas sólo participaban los vecinos de la respectiva cuadrilla, mientras que la participación en la primera era libre para todo el que lo desease, incluidos los forasteros que se hallasen en Soria para la ocasión.

Entre estas otras comidas cabe mencionar el almuerzo que había de dar el mayordomo el viernes "de novillos", por la mañana. Según las ordenanzas de la cuadrilla de San Esteban de 1544 era obligación de éste dar de almorzar a todos los vecinos de la cuadrilla de sexo masculino, y casados, que se juntasen en su casa ese día, los cuales, una vez concluido el almuerzo, debían proceder a nombrar todos los ofi-

\footnotetext{
${ }^{28}$ Un ejemplo de comida de "caridad" que se celebró en el pasado y ha dejado de celebrarse en la actualidad lo encontramos en la ciudad de Logroño, en cuyo archivo municipal se conserva un documento titulado "Remembranza de las rentas que ha la Caridad de la Ascensión del concejo de Logroño, e es establida por concejo, que se de el dia de la ascension". Otro ejemplo, tomado de una población mucho más pequeña, lo encontramos en Canillejas (Madrid), donde el día de la Natividad de la Virgen los vecinos del lugar celebraban una "caridad" que pagaban con sus propios dineros. AGS, RGS, III-1504 (1º). Provisión a los tesoreros y comisarios de la Cruzada del arzobispado de Toledo.
} 
cios para la caridad del domingo ${ }^{29}$. En este almuerzo no estaba previsto el consumo de carne, que era uno de los alicientes principales de la comida del domingo, sino que a los asistentes sólo se les ofrecía pescado, huevos, queso, verduras y fruta ${ }^{30}$. Como complemento a este almuerzo ofrecido el viernes por la mañana a los hombres casados, las mujeres que acompañaban el sábado a la mayordoma eran obsequiadas por el servidor de damas con otra pequeña colación o merienda, en la que se consumían aceitunas, queso, vino y fruta ${ }^{31}$. Los documentos no aclaran bien, sin embargo, cuál era el acto con ocasión del que se obsequiaba a las mujeres con este refrigerio, aunque es probable que se tratase de alguna celebración litúrgica ${ }^{32}$. De hecho ese mismo día también se ofrecía a los clérigos una colación, después del rezo de la Salve, pero debía ser de escasa importancia, ya que ocasionaba muy poco gasto ${ }^{33}$.

Este rezo de la Salve debía formar parte de los actos litúrgicos con que se festejaba la Vigilia de Nuestra Señora. Las ordenanzas de 1536 nos amplían la información, al indicar que aquella noche del sábado muchas personas tenían por costumbre ir a velar a las iglesias de Nuestra Señora del Espino y Nuestra Señora del Mercado. Pero también denunciaron que la mayoría, en lugar de limitarse a rezar, estaban "bozeando, tanendo tamborinos ... y otros ynstrumentos", y haciendo otras cosas que no resultaban decentes en las iglesias.

Todos los almuerzos y colaciones previstos para el viernes y el sábado pueden considerarse como festejos menores en comparación con la comida del lunes siguiente a la fiesta de Nuestra Señora, en la que participaban conjuntamente maridos y mujeres. Ésta, no obstante, tenía carácter optativo, y por este motivo llegaron a plantearse en ocasiones graves conflictos en el seno de las cuadrillas, porque unos vecinos insistían en que se celebrase, mientras que otros se negaban, apremiados por la necesidad de ahorrar. Un ejemplo de tales conflictos lo encontramos en la cuadrilla de San Pedro en el año $1592^{34}$. Ocurrió entonces que el acompañado designado para

\footnotetext{
${ }^{29}$ Según acta de reunión de la cuadrilla de San Esteban de 20-5-1601 el mayordomo "ha de dar de almorzar el viernes de los novillos a todos los hombres casados que hubiese en la cuadrilla lo que es costumbre". Libro de la cuadrilla de San Esteban, fol. 101v.

${ }^{30}$ El mayordomo de la cuadrilla de San Esteban gastó para este almuerzo en el año 1602 lo siguiente: 34 reales en pescado, 14 en mantecas, 10 en huevos, 26 en pesca (probablemente pescado de río, 8 en queso, 2 en vinagre, 3 en miel, 4 ducados en 3,5 cántaras de vino blanco, 14 reales en aceite, 20 en guindas y cerezas, y 4 en rábanos y lechugas. Libro de la cuadrilla de San Esteban, fol. 103v.

31 En las cuentas que se tomaron en Soria, 30-6-1608 al mayordomo de la cuadrilla de San Esteban, Cristóbal Sanz, éste declaró haber gastado 25 reales en aceitunas, queso y vino "para darles de merendar el sábado a las mujeres", más 3 reales en fruta. En otras ocasiones los documentos mencionan entre las obligaciones del mayordomo el dar de almorzar el sábado a las mujeres que fuesen a acompañar a la mayordoma. Libro de la cuadrilla de San Esteban, fol. 112v.

${ }^{32}$ Martín de Marco (1999: 131-134), habla de varias romerías de mujeres casadas y mozas que se celebraban el sábado, el domingo y el lunes, en las que eran obsequiadas por el sacador de mozas y el servidor de damas. Pero la base documental en que se sustentan sus afirmaciones es endeble.

33 Según las cuentas de la cuadrilla de San Esteban de 30-6-1608, sólo se gastaron 6 reales en la colación dada a los clérigos el sábado, después de la Salve. Hay que tener en cuenta, no obstante, que a financiar esta colación contribuirían todas las cuadrillas.

${ }^{34}$ Lo podemos reconstruir en parte con la información proporcionada por un documento en muy mal estado de conservación en AHPS, Corregimiento, Caja 5058.
} 
auxiliar al mayordomo en la organización de la fiesta murió antes de haber llegado la fecha de ésta. A raíz de ello el mayordomo Alonso de Mazuelo, sintiéndose quizás abrumado por el peso de la responsabilidad, que pasaba a recaer de forma exclusiva sobre su persona, manifestó que estaba dispuesto a seguir adelante y servir la fiesta, pero con la condición de que no se le obligase a dar la comida general del lunes, sino sólo "lo que toca a la caridad, y el santo y echar los oficios como se acostumbra hacer en otras cuadrillas". Un sector de los vecinos se mostró de acuerdo con prescindir de esta comida, y para ello otorgaron incluso declaraciones firmadas, en que manifestaban que no querían comer en la cuadrilla, ni almorzar, ni que hiciese el mayordomo gasto alguno con ellos. Otros, por el contrario, insistieron en exigir que dicha comida se celebrase, y, aunque el mayordomo recurrió ante el corregidor para que le liberase de la obligación de darla, finalmente accedió, pero con una serie de condiciones. Exigió en concreto que se le comunicase explícitamente cuáles eran los vecinos que querían participar en la comida, y a los que, por consiguiente, tenía que dar de comer el lunes, para de este modo no tener que hacer más gasto de lo necesario. Y, en segundo lugar, pidió que la cuadrilla nombrase dos personas que le acompañasen cuando fuese a comprar el pan, vino, carne y otras cosas necesarias, para así evitar futuros litigios y que no pudiesen acusarle de haberles cargado más de lo que se había gastado con ellos. El corregidor solventó finalmente el litigio ordenando que el mayordomo no guisase ni aderezase de comer para los vecinos de la cuadrilla que, después de haberse iniciado el pleito, habían declarado que no querían comer, y así se lo habían manifestado, pero que sí lo hiciese para el resto ${ }^{35}$.

Que la comida del lunes tenía un carácter opcional, ya había quedado bien sentado, sin embargo, en las ordenanzas de la cuadrilla de San Esteban de 1544, en las que se contemplaba explícitamente la posibilidad de que algunos años a los vecinos "les pareciere no comer, o por las carestías del año o por otros inconvenientes que podrían suceder". Para este caso, adelantaban el fin de la fiesta al propio lunes, día en que por consiguiente deberían reunirse los contadores designados por la cuadrilla para tomar cuentas al mayordomo saliente. Por el contrario, en los años en que se decidiese celebrar una comida el lunes, esta toma de cuentas se había de retrasar al martes, prolongándose de este modo un día más la fiesta. Para este caso las ordenanzas dispusieron que el mayordomo quedara obligado a dar a todos los vecinos su comida general de vaca y carnero, fruta, pan y vino, "Como se suele y acostumbra dar". Después de acabada la comida había de procederse a nombrar al mayordomo y demás oficios acostumbrados para el siguiente año. Y, por fin, también estaba contemplado que se pudiese bailar ${ }^{36}$. Nada se dice en estas ordenanzas, sin embargo,

${ }^{35}$ En su sentencia el corregidor ordenó también al jurado que hiciese juntar la cuadrilla para designar dos vecinos "de los que quisieren comer" para que éstos supervisasen el gasto que Alonso López de Mazuelo hiciere, y lo aprobasen, dejando constancia de su conformidad mediante la firma de un documento.

${ }^{36}$ Las ordenanzas literalmente dispusieron que ese lunes, después de la comida y de la elección de los oficiales, no se hiciese nada más, "si no fuese bailar". Que los bailes eran una forma de diversión habitual durante todos los días de la fiesta lo dejan entrever las ordenanzas de 1536 , cuando dispusieron que en adelante ninguna cuadrilla "hagan bailas ni danzas por las calles". En la actualidad el último día de la fiesta se conoce como "Lunes de Bailas", porque todos los vecinos bajan a bailar por la tarde a una pradera junto al Duero. 
acerca de que pudiese establecerse una diferenciación entre vecinos que quisiesen acudir a esta comida del lunes, y los que no lo deseasen. Ello explica que llegasen a plantearse conflictos como el de la cuadrilla de San Pedro del año 1592. En la práctica nos consta, no obstante, que a lo largo de todo el siglo XVI cuadrillas como la de San Esteban en bastantes ejercicios establecieron un diferente tratamiento para los vecinos que habían acudido a comer el lunes y los que no habían querido hacerlo, cargando a estos últimos una cuota menor en los repartimientos. Pero en ningún caso se les eximió totalmente de contribuir, pues se consideraba que también ellos estaban obligados a financiar los gastos generados por la comida de caridad del domingo y otros actos festivos de carácter religioso ${ }^{37}$.

En suma, las comidas en comunidad constituyeron un elemento central de las actividades festivas que las cuadrillas de Soria organizaban para honrar a la Virgen en los últimos días de junio, junto con las diversiones en torno al toro y los bailes. Dichas comidas tenían mucho de ritual que propiciaba el reforzamiento de los lazos comunitarios. De ahí que se entendiese que el "servicio" que debía prestar el mayordomo consistiese esencialmente en asegurar su celebración conforme a la costumbre inmemorial. Y de ahí también que a los vecinos a los que se daba por servido el oficio de mayordomo, a cambio de la entrega de una cantidad en dinero, habitualmente se les exigiese también que ofreciesen una "merienda" y "tendiesen manteles", pues se debía entender que de este modo prestaban también, aunque a una menor escala, el servicio de ofrecer una comida a la comunidad, la principal contribución a la fiesta que se esperaba de los mayordomos.

\section{LAS FIESTAS DE LAS COFRADÍAS SORIANAS}

Además de la fiesta de Nuestra Señora, otras varias celebraciones escaparon en Soria al control organizativo del concejo, pero no todas ellas presentan características semejantes. Hubo algunas, por el contrario, que tuvieron un marcado carácter elitista y en lugar de exaltar los valores de la solidaridad y la caridad, y buscar el reforzamiento de los vínculos comunitarios, trataron más bien de alimentar el espíritu de clase, ensalzando aquellos valores y prácticas que más contribuían a diferenciar al grupo participante frente al resto de la sociedad. Así ocurrió en concreto con las fiestas organizadas por la Diputación de los Doce Linajes, como organización estamental de los caballeros hidalgos (Sobaler 2007), y algunas cofradías exclusivistas, que sólo admitían en su seno a los miembros de dicho estamento, como fue el caso en Soria de las de Santa Catalina (Diago 2000: 565-7) y Santiago (Sobaler 1992). Hubo, no obstante, otras muchas cofradías que admitían en su seno a personas procedentes de un amplio espectro social, en las que convivieron pecheros, hidalgos y clérigos. Y es en las fiestas que organizaron algunas de estas cofradías de más amplia base social, o

\footnotetext{
${ }^{37}$ Por ejemplo la cuadrilla de San Esteban en 1548, para cubrir el déficit de 8.543 mrs. que había habido en la organización de la fiesta, acordó repartir medio real a las casas y tiendas, cinco reales a cada vecino que fue a comer; la mitad a las viudas ricas "y que lo pueden pagar", y lo mismo a los vecinos que no fueron a comer y a los clérigos. A las viudas pobres, por fin, se les repartió medio real "para la caridad y otros gastos".
} 
en aquéllas en que dominaba el elemento popular, donde encontramos mayor número de similitudes con la de Nuestra Señora, por estar todas ellas animadas por un mismo propósito de contribuir al reforzamiento de los lazos comunitarios, sin afán de exclusión o de exaltación de lo diferencial.

En las fiestas organizadas por las cofradías sorianas el toro no alcanzó el protagonismo que siempre tuvo, y sigue teniendo, en la fiesta de Nuestra Señora. No debía ser fácil obtener la autorización para correr toros en la ciudad y mucho menos consolidar el derecho a hacerlo de forma regular. No obstante, sabemos que la cofradía de San Roque sí que lo logró. Así, en 1589 el concejo de Soria acordó proporcionarle un toro para que lo corriesen y sacrificasen en la fiesta que celebraba en honor a su patrono en el arrabal, el día 16 de agosto, con la condición de que su carne fuese después distribuida por el procurador del Común y los fieles de los pobres ${ }^{38}$. Diez años después el mismo concejo acordó que no se diese a dicha cofradía el referido toro porque no lo gastaban en obras de caridad como estaban obligados ${ }^{39}$. Pero lo cierto es que la cofradía llegó a disponer de sus propios toros, a los que durante el siglo XVII se autorizó a pastar en la dehesa de Valonsadero, y que continuó conmemorando a su patrón con la corrida y sacrificio de uno en la plaza del arrabal, razón por la cual el concejo de Soria decidió en 1618 poner fin a la celebración de la corrida que desde tiempos bajomedievales había venido organizando en la plaza mayor para conmemorar la fiesta de la Asunción de la Virgen, para que no coincidiesen al mismo tiempo dos corridas en la ciudad ${ }^{40}$.

La cofradía de San Roque fue, no obstante, la única que pudo celebrar en Soria su fiesta principal con una corrida de toros, seguida de la comida ritual en que se consumía la carne del novillo sacrificado. A falta de toro que poder sacrificar después de haberse divertido con él corriéndolo por calles o plazas, fueron muchas las cofradías sorianas que no renunciaron por ello al consumo de esta carne en comidas comunitarias. La falta de documentación y de investigaciones previas, no nos permite conocer de forma exhaustiva cuáles fueron y qué características presentaron los actos organizados. Unos cuantos ejemplos bastarán, en cualquier caso, para demostrarnos que algunos de los ágapes de carácter comunitario celebrados por las cofradías ofrecen interesantes paralelos con los de la fiesta de Nuestra Señora.

La cofradía que, según todos los indicios, contó en Soria con mayor número de miembros, y con una base social más amplia y diversificada fue la de San Hipólito. Fundada en honor del rey Alfonso VIII, que nació el día en que la Iglesia celebraba la fiesta de este santo, era de las más antiguas y prestigiosas de la ciudad, hasta el punto que sólo pudo rivalizar con ella la de Santa Catalina, cuyo prestigio derivaba, no obstante, de su carácter exclusivista, pues sólo admitía en su seno a hidalgos (Diago 2000: 563-5). Las fiestas organizadas por esta cofradía, que desarrollaba además una importante función caritativa ${ }^{41}$, debieron ser por consiguiente un destacado aconteci-

\footnotetext{
38 Acta del concejo de Soria de 15-8-1589. En Salamanca fueron varias las cofradías que pudieron organizar regularmente corridas de toros, en muchos aspectos parecidas a la de San Roque (Lorenzo Pinar 2010).

39 Acta del concejo de Soria de 9-VIII-1599.

40 Acta del concejo de Soria de 23-IV-1618.

${ }^{41}$ Proporcionaba mortaja y cera para su entierro a todos los pobres que morían en la ciudad de Soria y además su preboste efectuaba varios repartos de limosnas a lo largo del año.
} 
miento de la vida social soriana. Lamentablemente es poco lo que sabemos sobre las mismas, pero al menos nos consta que contemplaban la celebración de una comida general que debía ser multitudinaria, a juzgar por las grandes cantidades de carne que en ella se consumían, pues, por ejemplo, para la que tuvo lugar en el año 1566 se sacrificaron 4 vacas y 35 carneros $^{42}$.

Más detalles poseemos sobre las comidas organizadas por otra cofradía con una base social mucho menos diversificada y más decididamente "popular". Nos referimos al cabildo de los Heros, o cofradía de Nuestra Señora de la Blanca, que agrupaba a todos los labradores residentes en la ciudad de Soria (Diago 2010). Celebraba su fiesta principal el día de la Natividad de la Virgen, 8 de septiembre, con ocasión de la cual se organizaba una comida de hermandad, de la que tenemos noticia porque en el año 1627 dos de los cuatros y diecisiete hermanos más tomaron la decisión de suprimirla "por excusar gastos", aunque sin perjuicio de poder reanudar su celebración en el futuro. Esta decisión fue declarada, no obstante, nula por el preboste, por no haber sido él convocado para aprobarla ni contar con el respaldo de la mayoría. Una vez más nos volvemos a tropezar con la situación ya detectada en algunas cuadrillas sorianas, que nos pone de manifiesto cómo las graves dificultades económicas que se abatieron sobre la ciudad de Soria a partir de las últimas décadas del siglo XVI alimentaron las tensiones en las asociaciones de vecinos, sobre si procedía continuar celebrando las comidas comunitarias que para muchos conllevaban un insoportable sacrificio financiero.

El cabildo de los Heros, además de esta comida de su fiesta principal, celebraba otras, en la fiesta del primero de mayo y en la de San Martín de Tours, el 11 de noviembre. Un hallazgo documental nos permite conocer algunos detalles de esta última comida, en concreto de la que se celebró el año 1618, a la que asistieron 52 escoteros. Lo más sobresaliente de la misma es que en su transcurso se procedió a subastar los despojos de los carneros y vacas sacrificados para el consumo, en una ceremonia calificada como "echar los axejues", que presenta evidentes paralelismos con las que se organizaban en las cuadrillas el día de la fiesta de Nuestra Señora y en otras cofradías sorianas en sus correspondientes fiestas principales.

Por lo que respecta a las cuadrillas, las subastas de piezas del toro, conocidas como "ageses", siguen constituyendo hoy en día un elemento esencial de las llamadas fiestas de San Juan ${ }^{43}$. Disponemos de testimonios documentales de su celebración ya en los siglos XVI y XVII, aunque entonces no tenían lugar el sábado, que por eso se llama ahora "de agés", sino el domingo, después de la comida de caridad. Un ejemplo ilustrativo nos lo proporciona el acta notarial que da fe de la reunión que tuvieron los vecinos de la cuadrilla de Santo Tomé en la casa del jurado el 30 de junio de 1641 "para efecto de vender y hacer ajegues en ella una parte de un buey que la cuadrilla tiene, de lo que sobró de la fiesta que se ha hecho hoy día de Nuestra Señora " ${ }^{44}$. El procedimiento de subasta de la piezas del buey que se siguió en esta re-

${ }^{42}$ AHPS, PN, 15-40-155.

43 El actual término "agés", que deriva de los términos "ajegues" y "ajexues" utilizados en los siglos anteriores, constituye de hecho un curioso sorianismo, de difícil etimología Algunas consideraciones, discutibles, sobre el vocablo "agés" y sus variantes en Martín de Marco (1999: 109-111).

${ }^{44}$ AHPS, PN, 608-1033-522, Soria, 30-VI-1641. Las piezas subastadas, con su correspondiente precio en reales, fueron las siguientes: cabeza del buey (3 reales), pecho (3), pedazo de garrón (1), 
unión fue idéntico al constatado en la comida general del cabildo de los Heros el 11 de noviembre de 1618, utilizándose en los dos casos la expresión de "ajegues" o "ajexues" para referirse a él. Por otra parte, en los dos casos se concedió un generoso aplazamiento de pago, de casi un año, a los vecinos en quienes se remataron los distintos despojos ${ }^{45}$. Esto demuestra, por tanto, que la costumbre, al margen de su indiscutible significado ritual, venía a asumir también una función caritativa que enlazaba con el espíritu primordial de la fiesta. Además de las cuadrillas, nos consta que otras varias cofradías de la ciudad de Soria incluyeron entre sus celebraciones estas subastas de despojos de reses. Es el caso de la de San Pelegrín que, en una reunión del 5 de noviembre de 1581, subastó entre los asistentes varios pechos de carnero, y entraldas, ubres, espaldas y piernas de vaca, además de pellejos y sebo de carneros y vaca ${ }^{46}$. Por su parte, la de Santa Bárbara, de la que formaban parte preferentemente labradores, podemos deducir por indicios que también las practicaba, pues Domingo Logroño, que había sido su preboste en el año 1669, declaró en una ocasión que algunos cofrades escoteros de la cofradía le estaban adeudando dinero "del escote a que salieron y se les repartió para dicho año", y por razón de las piezas de vaca que se les habían vendido ${ }^{47}$.

Además de las comidas en las que el consumo de carne de carnero y vaca o toro era un componente fundamental, las cofradías sorianas también contemplaron entre sus celebraciones algunos otros refrigerios de carácter más ligero, en los que la ingesta de alcohol, en concreto de vino, debía representar el principal aliciente. Como prueba sirva recordar la colación ofrecida por el preboste de la cofradía de las Ánimas del Purgatorio el día de su fiesta principal, el 4 de octubre. Por las cuentas que rindió del ejercicio 1624-1625 al finalizar su mandato ${ }^{48}$, sabemos que gastó para dicha colación 431 reales, que empleó en la compra de vino, melocotones, queso y pan. Dado que los melocotones y el vino han sido ingredientes básicos para la elaboración del "zurracapote", omnipresente en las tradicionales fiestas de los pueblos sorianos, podríamos tener aquí un testimonio de su consumo en estas colaciones con las que algunas cofradías sustituyeron las comidas generales a base de carne de vacuno y carnero, sin duda mucho más costosas.

Las comidas y colaciones organizadas por las cofradías presentaban, por lo demás, otro interesante rasgo en común con las que las cuadrillas celebraban durante la fiesta de Nuestra Señora. Nos referimos al hecho de que en todas ellas se contemplaba como procedimiento básico de financiación el pago de un escote por los asistentes. Así, por ejemplo, para la aludida colación del 4 de octubre de la cofradía de las Ánimas del Purgatorio, el preboste recaudó de las personas que entraron como cofrades a recibirla un total de 239 reales, a razón de real por persona; lo que nos

pieza de pecho (5), lengua (4), palomilla (5), palomilla (4), falda (3) falda (3,75), lomo (7), lomo $(5,5)$, espalda $(12,5)$, espalda $(12,5)$, pierna $(31,5)$, pellejo $(37,5)$.

${ }^{45}$ En la subasta efectuada por el cabildo de Los Heros, que tuvo lugar el 11 de noviembre, el plazo de pago se fijó para la fiesta de Nuestra Señora de Septiembre del año siguiente. En la de la cuadrilla de Santo Tomé, que se efectuó el 30 de junio, se aplazó el pago hasta el primero de mayo del año siguiente.

46 AHPS, PN, 26-68-222, Soria, 5-11-1581.

${ }^{47}$ Carta de poder en Soria, 11-1-1672. AHPS, PN, 785-1269-11.

48 AHPS, PN, 531-906-261, Soria, 12-10-1625. 
confirma el carácter multitudinario de la reunión. Ciertamente con este dinero apenas bastó para cubrir un poco más de la mitad del gasto total, que ascendió a 431 reales, pero se debió preferir no gravar en exceso los maltrechos bolsillos de los cofrades por existir otras fuentes de ingresos. Por lo demás, las referencias a escotes y escoteros en documentos relativos a otras cofradías sorianas son relativamente abundantes, no dejando lugar a dudas sobre la generalización de este procedimiento de financiación de sus comidas comunitarias.

Las cofradías, por lo demás, incorporaron algunos otros festejos de muy diversa índole, entre los que cada vez fueron encontrando un mayor hueco los de declarado carácter profano. Así, en el siglo XVII nos consta que algunas, como la del Santísimo Sacramento, con sede en la iglesia parroquial de Nuestra Señora del Espino, organizaron la representación de comedias, para las cuales contrataron acompañamiento musical $^{49}$. Y, junto a las comedias, también alcanzaron creciente popularidad los desfiles de inspiración profana, que se incorporaron a las procesiones. Es el caso de la llamada zuiza, o desfile de individuos disfrazados de soldados, con la que en la segunda mitad del siglo XVII el cabildo de los Heros, o cofradía de La Blanca, contribuía a la procesión que la ciudad de Soria organizaba en honor de su santo patrón, San Saturio (Diago 2010: 46-47).

\section{CONCLUSIÓN}

La fiesta de la boda de Santa María, que tan arraigada estaba en la vida social de la ciudad de Soria en la segunda mitad del siglo XV, cuando a los propios judíos que allí residían se les quería obligar a contribuir a su financiación, continúa celebrándose en la misma fecha todavía en estos inicios del siglo XXI. Es un vestigio, muy transformado, de otros tiempos y de una sociedad muy distinta a la soriana actual, en la que la amenaza de la pobreza era mucho mayor, e incidía en muy mayor medida en la conformación de la visión del mundo de las gentes. Pero, por su propia capacidad de perduración, esta singular fiesta ofrece al investigador social un interesante objeto de estudio y reflexión, que no siempre ha sido abordado con el suficiente rigor, pues con frecuencia ha sido manifiestamente tergiversada, olvidando su origen medieval y poniéndola en relación con oscuras tradiciones de origen celtibérico, sin otro argumento que la pura especulación.

En el presente trabajo hemos querido llamar la atención sobre algunos de los rasgos más singulares de la fiesta en el pasado, tal y como nos permite percibirlos la documentación conservada, que es tardía y a veces muy poco explícita. Muy en particular hemos tratado de poner de manifiesto su perfil de celebración de base popular, organizada al margen de las principales instancias de poder local, que no dejaron de mirarla con cierto recelo y preocupación por su potencial subversivo, y trataron por ello en varias ocasiones de reformarla mediante el otorgamiento de ordenanzas,

\footnotetext{
${ }^{49}$ AHPS, PN, 102-227-247, Soria, 1-6-1608. El preboste de la cofradía del Santísimo Sacramento contrata a tres ministriles, para que sirvan en la dicha cofradía la fiesta del Santísimo Sacramento el próximo viernes 6 de junio, fiesta principal de la cofradía, a misa y a vísperas y en la comedia que se ha de hacer en la iglesia de Nuestra Señora del Espino el referido día.
} 
aunque sin éxito aparente a medio plazo ${ }^{50}$. También es cierto, no obstante, que en el plano político este potencial subversivo de la fiesta no llegó a traducirse, por lo que de momento sabemos, en graves desafíos al statu quo. Y ello contribuiría a explicar que las autoridades concejiles no sintiesen excesivo apremio por llevar adelante sus proyectos reformadores o intervencionistas, y pronto renunciasen a ellos, ante la fuerte resistencia ofrecida por el grueso de la población pechera.

Por otro lado, también se ha intentado situar la fiesta en su contexto, llamando la atención sobre los paralelismos que en algunos puntos presenta con otras celebraciones organizadas en el pasado por asociaciones hoy desaparecidas. Muchos de estos paralelismos, a los que merecería darse mayor desarrollo, cabe detectarlos con fiestas también dedicadas a Nuestra Señora en aldeas de la Tierra de Soria, como es el caso de Vinuesa o Aldealseñor, para las que se conservan ordenanzas de comienzos del siglo XVI, que, entre otras cuestiones, regulan la organización de dicha fiesta, financiada a escote entre todos los vecinos, incluidos los que no deseaban participar en ella ${ }^{51}$.

La que hemos analizado es una de las pocas fiestas de raigambre popular, con origen bajomedieval, que persisten en la España postindustrial de comienzos del siglo XXI. Por ello hemos entendido que el análisis de sus características en el pasado podía resultar de interés para los antropólogos que abordan el estudio de la fiesta y sus rituales como un elemento fundamental de la cultura popular. Ofrecería sin duda notable interés realizar un trabajo basado en la observación de las formas que adopta en la actualidad la celebración de esta fiesta en Soria, para comparar con lo que hemos conseguido averiguar sobre cómo se celebraba en el pasado. De este modo podríamos valorar mejor en qué medida ha sufrido una evolución o ha quedado desvirtuada, y hasta qué punto ha podido perder su significado primigenio, afectada por los enormes cambios acontecidos en los dos últimos siglos en los terrenos social, político e institucional, y por las transformaciones experimentadas por las creencias generales, en las que los elementos mágicos han experimentado un evidente retroceso, aunque sin desaparecer de forma radical. Es tarea que no podemos acometer aquí y que corresponderá a los antropólogos llevar a cabo. Pero para que se haga efectivo el diálogo interdisciplinar, hemos querido al menos poner a su disposición algunos nuevos materiales que, en el desempeño de nuestra profesión de historiadores, hemos logrado arrancar de los archivos, ya no tan polvorientos como antaño, pero, por lo que respecta a su utilización para el trabajo de investigación, igualmente desatendidos.

\section{BIBLIOGRAFÍA CITADA}

Álvarez García, C. 1995. "Sobre el origen de las fiestas de Vinuesa y de San Pedro Manrique". Revista de Soria 10: 7-26.

\footnotetext{
${ }^{50}$ Además del intento más conocido de los años 1536-1540, hubo al menos otro importante en 1608, cuando por orden del corregidor se suprimieron ciertos oficios de las cuadrillas, como los de servidor de damas y sacador de mozas, y se ordenó que la carne del toro en la comida de la caridad se diese cruda en lugar de cocida, con la consiguiente supresión de la caldera.

${ }^{51}$ De dichas ordenanzas se conservan copias en el Archivo Histórico Provincial de Soria.
} 
Batjin, M. 1971. La cultura popular en la Edad Media y el Renacimiento. El contexto de François Rabelais. Barcelona: Montaner y Simón.

Beceiro Pita, I. 2009. "La intervención de la autoridad en las celebraciones religiosas. Las fiestas de Benavente y su Tierra (1434-1525)". Edad Media. Revista de Historia 10: 199-224.

Burke, P. 1978. Popular Culture in early modern Europe. Londres: Temple Smith.

Caro Baroja, J. 1974. "Las Mondas de Talavera", en Ritos y mitos equívocos. Madrid: Istmo: 31-51.

Casini, M. 1996. I gesti del principe. La festa politica a Firenze e Venezia in età rinascimentale. Venecia: Marsilio.

Decroisette, F. y Plaisance, M. (eds.). 1993. Les Fêtes urbaines en Italie à l'époque de la Renaissance. Vérone, Florence, Sienne, Naples. Langres : Impr. Guéniot.

Diago Hernando, M. 2000. "Soria y su Tierra en el obispado de Osma durante los siglos XV y XVI. Organización eclesiástica y práctica religiosa", en XIV Centenario Diócesis Osma-Soria. Premios de Investigación: 425-574.Soria: Diputación Provincial.

Diago Hernando, M. 2003. "La celebración de la fiesta en la ciudad de Soria a fines de la Edad Media y comienzos de la Edad Moderna (Siglos XV-XVII)". Revista de Soria 42: 63-78.

Diago Hernando, M. 2004. "La participación de los pecheros en la vida política de las ciudades castellanas: El Común de pecheros de Soria entre los siglos XIV y XVII". Celtiberia 98: 63-118.

Diago Hernando, M. 2008. "Las cuadrillas del Común de pecheros, una institución singular en la historia de la ciudad de Soria entre los siglos XIV y XXI". Revista de Soria 60: 31-46.

Diago Hernando, M. 2010. "El cabildo de los Heros y los labradores en la ciudad de Soria entre los siglos XV y XVII". Celtiberia 104: 5-48.

Díaz Viana, L. y Martínez Laseca, J. M․ 1992. De boy en un... año". Ritos y tradiciones de Soria. Soria: Diputación Provincial.

Fernández Juárez, G. y Martínez Gil, F. (eds). 2002. La fiesta del Corpus Christi. Cuenca: Universidad de Castilla-la Mancha.

García-Cuerdas, J. A. 2006. Villoslada de Cameros: Pueblo de hidalgos, trashumantes y emigrantes. Logroño: Instituto de Estudios Riojanos.

Ladero Quesada, M. A. 2004. Las fiestas en la cultura medieval. Barcelona: Debate.

Lorenzo Pinar, F. J. 2010. Fiesta religiosa y ocio en Salamanca en el siglo XVII (1600-1650). Salamanca: Universidad.

Löther, A. 1999. Prozessionen in spätmittelalterlichen Städten. Politische Partizipation, obrigkeitliche Inszenierung, städtische Einheit. Köln-Wien-Weimar: Böhlau.

Martín Cea, J. C. 1998. "Fiestas, juegos y diversiones en la sociedad rural a fines de la Edad Media". Edad Media. Revista de Historia 1: 111-42.

Martín de Marco, J. A 1999. Diccionario de términos sanjuaneros, glosario del vocabulario festivo. Soria: Caja Rural.

Massip Bonet, F. 2003. La monarquía en escena. Teatro, fiesta y espectáculo del poder en los reinos ibéricos: de Jaume El Conquistador al Príncipe Carlos. Madrid: Dirección General de Promoción Cultural.

Muir, E. 1981. Civic Ritual in Renaissance Venice. Princeton: Princeton University Press.

Narbona Vizcaíno, R. 2003. Memorias de la ciudad. Ceremonias, creencias y costumbres en la bistoria de Valencia. Valencia,:Ayuntamiento.

Peyer, H. 1955. Stadt und Stadtpatron im mittelalterlichen Italien. Zurich: Universitat.

Rivas Rivas, J. C. 1983. "Historia de la fiesta y caridad del glorioso San Marcos que se venera en la villa de Aldeire". Gazeta de Antropología 2: 36-40.

Rogge, J. 2003. "Stadtverfassung, städtische Gesetzgebung und ihre Darstellung in Zeremoniell und Ritual in deutschen Städten vom 14. bis 16. Jahrhundert", en Chittolini, G. y Johanek, P. (eds.), Aspetti e componenti dell'identità urbana inItalia e in Germania (Secoli XIV-XVI): 193-226. Bolonia-Berlín: Il Mulino-Duncker y Humblot.

Sobaler, Ma․ A. 1992. "La cofradía de nobles caballeros de Santiago de Soria (1572): Un intento frustrado de corporativismo nobiliar". Investigaciones Históricas 12: 11-29.

Sobaler, Ma . A. 2007. "Presencia y participación de los doce linajes de Soria en las fiestas y celebraciones urbanas", en Núñez Roldán, F. (coord.), Ocio y vida cotidiana en el mundo bispánico en la Edad Moderna: 417-426. Sevilla: Universidad de Sevilla. 
Suárez Fernández, L. 1964. Documentos acerca de la expulsión de los judios. Valladolid: CSIC.

Schwerhoff, G. 1994. "Das rituelles Leben der mittelalterlichen Stadt. Richard C. Trexlers Florenzstudien als Herausforderung für die deutsche Geschichtschreibung”. Geschichte in Köln 35: 33-60.

Terxler, R. 1980. Public Life in Renaissance Florence. Nueva York: Academic Press.

Ventrone, P. 2003. "Feste e rituale civici: città italiane a confronto", en Chittolini, G. y Johanek, P. (eds.), Aspetti e componenti dell'identità urbana in Italia e in Germania (Secoli XIV-XVI): 155191. Bolonia-Berlín: Il Mulino-Duncker y Humblot.

Vincent, C. 1994. Les confréries médiévales dans le royaume de France. XIIIe-XVe. Siècle. París: Albin Michel.

Fecha de recepción: 14 de septiembre de 2011

Fecha de aceptación: 21 de diciembre de 2012 